\title{
Sympathetic influences on the consensual ophthalmotonic reaction
}

\author{
MARY V GIBBENS \\ From the Department of Clinical Pharmacology, St Thomas's Hospital Medical School (UMDS), \\ London SE1 7EH
}

SUMMARY Six patients with intraocular hypertension received $0.5 \%$ timolol or saline uniocularly with saline to the other eye, and the intraocular pressure was measured by applanation tonometry at $0,30,60,120$, and 240 minutes. Falls in pressure were seen in both the timolol treated and consensual eyes. The same experiments were conducted after pretreatment of the consensual eyes with guanethidine $5 \%$. The consensual ophthalmotonic reaction (COR) to timolol administration was blocked by pretreatment with guanethidine. Three out of four patients with Horner's syndrome also showed a reduced COR in the affected eye after timolol administration to the normal eye, suggesting that the COR is mediated by a nervous reflex with the efferent limb in the sympathetic nervous system.

The consensual ophthalmotonic reaction (COR) describes the phenomenon whereby alteration of the intraocular pressure (IOP) in one eye is accompanied by a corresponding pressure change in the contralateral eye. It has been postulated that the COR is mediated via a nervous reflex mechanism; however, the pathways involved have not been shown. Prijot and Stone, ${ }^{1}$ using uniocular compression as their initiating stimulus, found that the COR was not observed in atropinised rabbits and concluded that the parasympathetic nervous system might be involved.

Perkins, ${ }^{2}$ using stimulation of the fifth cranial nerve in rabbits to alter the IOP, found that the COR was diminished by profound narcosis and abolished by section of the fifth nerve on the consensual side, and he suggested that an axon reflex with the efferent limb in the fifth nerve might exist. Akagi et al., ${ }^{3}$ however, in experiments where they artificially raised the IOP in the treated eye to provoke a consensual response, found that section of the fifth nerve on the treated side prevented the COR; and that the COR was inhibited by blocking the cervical sympathetic on the consensual side. Akagi et al. therefore deduced that the sympathetic nervous system might provide the efferent limb of the reflex.

The aim of this study was to determine whether

Correspondence to Dr Mary V Gibbens, Department of Ophthalmology, St Thomas's Hospital, London SE1 7EH. sympathetic dysfunction, whether induced by disease or drug, altered the COR in the human eye.

\section{Subjects and methods}

SUBJECTS

The study group for experiment 1 comprised six ocular hypertensive volunteers, five male and one female, aged 45 to 76 , with an IOP $>21 \mathrm{mmHg}$ in one or both eyes on three or more occasions but without glaucomatous visual field loss or optic disc cupping and with open drainage angles.

The study group for experiment 2 consisted of four volunteers, three male and one female, aged 28 to 54 with unilateral Horner's syndrome. Each showed features of ptosis and a small pupil with a slow redilatation phase of the light reflex, as seen on pupillometric measurement, and diminished response to the topical instillation of cocaine $4 \%$. None was receiving any ocular or systemic therapy.

\section{METHODS}

\section{Experiment 1}

Every subject attended on four occasions at the same time of day, each separated by at least one week. Prior to two of these visits pretreatment with one drop of guanethidine $5 \%$ was administered by the subject to the right eye twice daily for three days. 
Prior to the other two visits the subjects received no pretreatment. On the experimental days the subjects received either one drop of timolol $0.5 \%$ to the left eye and saline to the right eye or saline to both eyes. This drug administration was carried out under double-blind conditions according to a factorial design (see Table 1).

IOP measurements were taken before and at 30 , $60,120,240$, and 360 minutes after drug administration. Measurements were taken in both eyes (right eye first on each occasion) by applanation tonometry under topical $0.4 \%$ benoxinate anaesthesia. Three measurements were taken for each reading and averaged.

Repeatability was assessed by calculation of the coefficient of variation for the starting pressures within occasions and between occasions for the visits when no pretreatment was administered.

\section{Experiment 2}

Each of the four patients with Horner's syndrome attended on three occasions. On one occasion one drop of $0.5 \%$ timolol was instilled into the affected eye and saline to the normal eye. On another visit saline was administered to both eyes, and on a third visit timolol was instilled into the normal eye and saline to the affected eye. The treatment order was randomly selected and applied double blind.

IOP measurements were made before and at 30 , $60,120,240$, and 360 minutes after treatment.

\section{STATISTICAL METHODS}

For each series of experiments IOP changes as a function of time were calculated for the treated and consensual eyes as the area under the curve (AUC) from the time of treatment administration using the trapezoid rule. The results from the six ocular hypertensives were averaged. The 'integrated drug effect' was calculated by subtracting the values obtained for the saline experiments from those of the timolol experiments in order to exclude any effect that repeated tonometry or diurnal variation might have on IOP.

\section{Results}

\section{EXPERIMENT 1}

The mean starting IOP for the six ocular hypertensives was $21.9 \mathrm{mmHg}$. The coefficient of variation for the starting IOPs on the non-pretreatment days was $3.4 \%$ within occasions and $9.6 \%$ between occasions. The mean AUCs for each eye and each study day are shown in Table 1 .

When no pretreatment was given and saline was administered to both eyes (visit D), the IOP changes with time were small, representing diurnal variation and any effect that repeated applanation might have on IOP. The calculated AUC for both eyes under these circumstances was not significantly different from zero.

When timolol was administered to the left eye in the absence of pretreatment (visit C), a fall in IOP was seen in both treated and consensual eyes. The AUCs were statistically significant for both eyes $(p<0.0025$ for the treated eyes and $p<0.025$ for the consensual eyes).

The integrated drug effect (shown in Table 1) for the timolol treated eyes was $39.0 \mathrm{mmHg}$. min and for the consensual eyes was $25.5 \mathrm{mmHg}$. $\mathrm{min}(\mathrm{p}<0.0025$ and $\mathrm{p}<0.05$, respectively).

Guanethidine pretreatment lowered the starting IOP by $4.81 \pm 0.9 \mathrm{mmHg}($ mean \pm SEM $)$ in the treated eye and by $1.55 \pm 0.4 \mathrm{mmHg}$ in the contralateral eye. Analysis of variance showed the difference in starting

Table 1 Mean area under curve and integrated drug effect in $\mathrm{mmHg} . \min ( \pm S E M)$ for timolol and saline treated eyes with and without pretreatment with guanethidine

\begin{tabular}{|c|c|c|c|c|c|c|c|c|}
\hline \multirow[b]{2}{*}{ Eye } & \multicolumn{2}{|l|}{ Visit $A$} & \multicolumn{2}{|l|}{ Visit $B$} & \multicolumn{2}{|l|}{ Visit $C$} & \multicolumn{2}{|l|}{ Visit $D$} \\
\hline & Right & Left & Right & Left & Right & Left & Right & Left \\
\hline Pretreatment & Guaneth & & Guaneth & Nil & Nil & Nil & $\mathrm{Nil}$ & Nil \\
\hline Treatment & Saline & Timolol & Saline & Saline & Saline & Timolol & Saline & Saline \\
\hline Mean AUC & 11.9 & $25 \cdot 8$ & $10 \cdot 6$ & $1 \cdot 3$ & $21 \cdot 4$ & $36 \cdot 6$ & $-4 \cdot 0$ & $-2 \cdot 4$ \\
\hline SEM & $5 \cdot 4$ & $8 \cdot 3$ & 3.9 & $2 \cdot 2$ & $7 \cdot 3$ & $7 \cdot 8$ & $4 \cdot 5$ & $3 \cdot 2$ \\
\hline \multirow[t]{2}{*}{$\mathrm{p}$} & $<0.05$ & $<0.0125$ & $<0.025$ & NS & $<0.025$ & $<0.0025$ & NS & NS \\
\hline & \multicolumn{4}{|c|}{ Visit $A$ minus visit $B$} & \multicolumn{4}{|c|}{ Visit $C$ minus visit $D$} \\
\hline Eye & Right & & Left & & Right & & Left & \\
\hline \\
\hline $\begin{array}{l}\text { drug effect } \\
\text { SEM }\end{array}$ & $\begin{array}{l}0 \cdot 4 \\
6 \cdot 5\end{array}$ & & $\begin{array}{r}24 \cdot 5 \\
7 \cdot 8\end{array}$ & & $\begin{array}{l}25 \cdot 5 \\
10 \cdot 9\end{array}$ & & $\begin{array}{r}39 \cdot 0 \\
7.7\end{array}$ & \\
\hline $\mathrm{p}$ & NS & & $<0.025$ & & $<0.05$ & & $<0.0025$ & \\
\hline
\end{tabular}


IOP to be significant in the pretreated eye $(p<0 \cdot 01)$ but not in the contralateral eye.

When guanethidine pretreatment was given and saline administered to both eyes (visit B), a fall in IOP was seen in the pretreated eyes during the study day. The AUC for the pretreated eyes was significantly different from zero $(\mathrm{p}<0.025)$ but for the fellow eyes it was not.

Pretreatment of the right eyes with guanethidine followed by treatment of the left eyes with timolol (visit A) resulted in a fall in IOP in both the timolol treated and consensual eyes. The AUCs for both eyes were statistically significant (p 140.0125 for the treated eyes and $\mathrm{p}<0.05$ for the consensual eyes).

AUCs from the guanethidine and saline study were subtracted from those of the guanethidine and timolol study in order to exclude the effect on IOP that guanethidine itself was seen to produce. The resulting drug effect for the timolol treated eyes was $24.5 \mathrm{mmHg} \cdot \mathrm{min}(\mathrm{p} .<0.025)$ and for the consensual pretreated eyes was $0.4 \mathrm{mmHg}$.min, which was not statistically significant. Thus uniocular treatment with timolol causes a fall in IOP in both the treated and consensual eyes; however, the consensual response is blocked by pretreatment with guanethidine.

\section{EXPERIMENT 2}

The AUCs for both the normal and affected eyes of the four patients with Horner's syndrome on each of their three visits are shown on Table 2. The AUCs for both eyes on the saline study day were subtracted from those on the timolol study days to exclude the effects of diurnal variation.

When timolol was administered to the normal eyes a fall in IOP resulted, with AUCs ranging from $16 \cdot 2$ to $28.3 \mathrm{mmHg}$. min. in the treated eyes. A variable response was seen in the consensual, Horner's affected eyes with AUCs ranging from -4.5 to 12.9 mmHg.min. In only one subject was a convincing consensual ophthalmotonic reaction seen.

When timolol was administered to the affected eyes a fall in IOP occurred in that eye in only three of the four subjects. In two of these three a consensual ophthalmotonic reaction was seen in the fellow, normal eye.

\section{Discussion}

The results from experiment 1 show that, in a group of six ocular hypertensive subjects who display a significant consensual ophthalmotonic reaction to uniocular timolol administration, pretreatment of the consensual eye with guanethidine blocks the response. This result agrees with that found by Akagi et al. ${ }^{3}$ In their experiments on animals, blockade of the cervical sympathetic on the side of the untreated eye inhibited the COR produced by an increase in IOP in the fellow eye. Their conclusion that the COR might be mediated by a nervous reflex with the efferent limb provided by the sympathetic nervous system is further supported by the findings of experiment 2, where, following timolol application to the normal eye, three out of the four Horner's syndrome patients showed a minimal COR in the sympathetically denervated eye. None of the present series of experiments support the findings of Perkins, ${ }^{2}$ who in a small number of animals noted that sympathectomy on the contralateral side facilitated the COR.

Table 2 Area under curve and integrated drug effect in $\mathrm{mmHg}$. min after timolol and saline treatments to affected and normal eyes in patients with Horner's syndrome

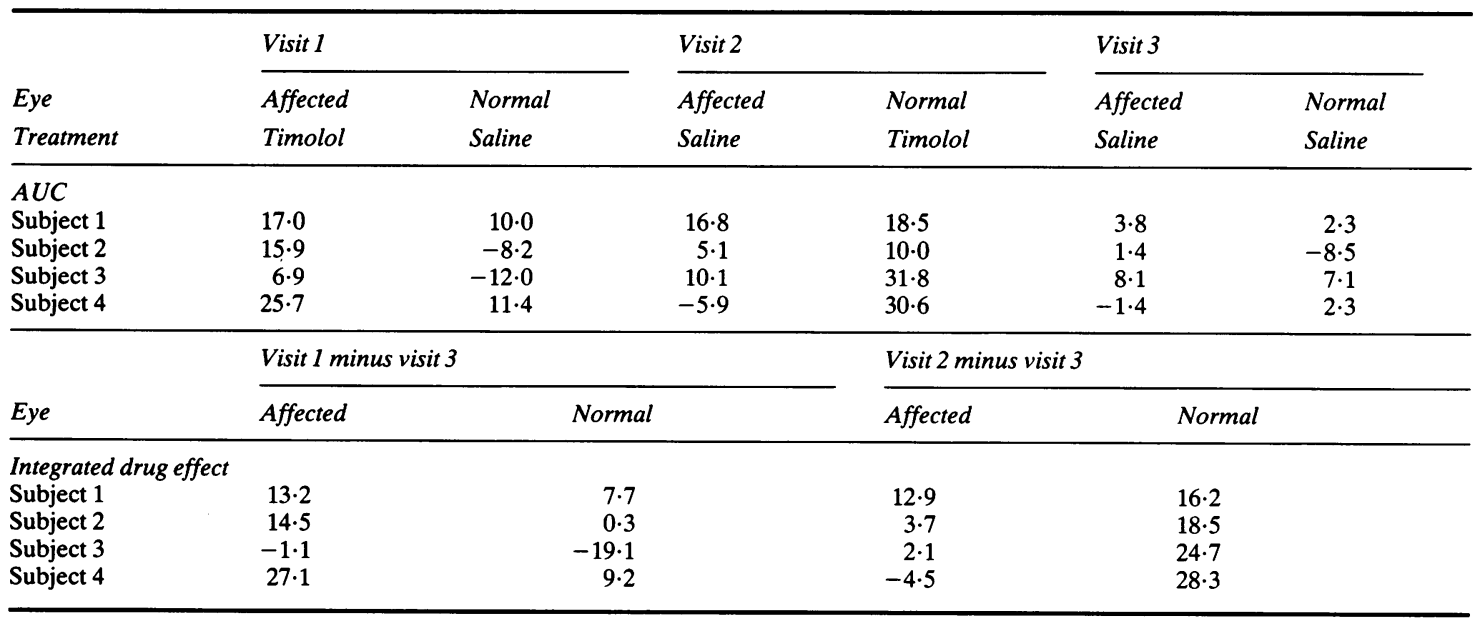


The Horner's syndrome patients also showed a poor COR in the normal eyes after timolol administration to the affected eyes. This could either be explained by postulating involvement of the sympathetic nervous system in the afferent as well as the efferent limb of the reflex, or it may be due to the reduced direct response to timolol seen in these eyes as compared with the normal eyes - a smaller direct response providing less stimulus for the consensual reaction. It is of interest to note that, in contrast to the present findings, Wentworth and Brubaker ${ }^{4}$ found in their study of aqueous humour dynamics in patients with third neurone Horner's syndrome, that the direct response to timolol was the same for both normal and affected eyes.
This study was supported by a grant from the Research (Endowments) Committee, St Thomas's Hospital, and by Merck, Sharp and Dohme Limited.

\section{References}

1 Prijot EL, Stone $\mathrm{HH}$. On the ophthalmotonic consensual reaction and its relationship to aqueous humour dynamics. Am J Ophthalmol 1956; 42: 50-8.

2 Perkins ES. Influence of the fifth cranial nerve on the intraocular pressure of the rabbit eye. Br J Ophthalmol 1957; 41: 257-300.

3 Akagi G, Nishimura K, Yamamoto A. Supplementary studies on the consensual ophthalmotonic reaction II. The relation between the consensual ophthalmotonic reaction and the cervical sympathetic or the trigeminal nerve. Ganka-Kiyo 1955; 6: 180-90.

4 Wentworth WO, Brubaker RF. Aqueous humour dynamics in a series of patients with third neuron Horner's syndrome. Am J Ophthalmol 1981; 92: 407-15.

Accepted for publication 2 July 1987. 